\title{
HOMOCYSTINURIA: A NEW INBORN ERROR OF METABOLISM ASSOCIATED WITH MENTAL DEFICIENCY
}

\author{
BY
}

\author{
NINA A. J. CARSON*, D. C. CUSWORTH $\dagger$, C. E. DENT $\dagger$, C. M. B. FIELD \\ D. W. NEILL $\S$ and R. G. WESTALL $\dagger$ \\ From Royal Belfast Hospital for Sick Children, University College Hospital Medical School, London, \\ Belfast City Hospital, and Royal Victoria Hospital, Belfast
}

(RECEIVED FOR PUBLICATION MARCH 20, 1963)

It is now becoming generally noted that many diseases of hitherto unknown aetiology are due to inborn errors of metabolism in the sense in which Garrod (1923) used this term. Although these diseases cover the whole of medicine it has been particularly gratifying to note that mental disease, especially mental deficiency which currently is responsible for one of our main medical problems, has been especially involved in these recent discoveries. In particular, a number of inborn errors of metabolism causing mental disease have been described recently in which the disorder concerned the metabolism of one or more of the amino acids. Of these, in addition to phenylketonuria which was described by Fölling in 1934, we now have Hartnup disease (Baron, Dent, Harris, Hart and Jepson, 1956), the occulo-cerebro-renal syndrome (Lowe, Terrey and MacLachlan, 1952; Denys, Corbeel, Eggermont and Malbrain, 1958), cystathioninuria (Harris, Penrose and Thomas, 1959), argininosuccinic aciduria (Allan, Cusworth, Dent and Wilson, 1958; Dent, 1959), maple syrup urine disease (Dancis, Levitz and Westall, 1960; Dent and Westall, 1961), hyperglycinaemia (Childs, Nyhan, Borden, Bard and Cooke, 1961), familial hyperprolinaemia (Schafer, Scriver and Efron, 1962) and citrullinuria (McMurray, Mohyuddin, Rossiter, Rathbun, Valentine, Koegler and Zarfas, 1962). Another gross disorder of amino acid metabolism involving histidine (Ghadimi, Partington and Hunter, 1961; Auerbach, Di George, Baldridge, Tourtellotte and Brigham, 1962) is also described but without as yet very tangible clinical consequences, two of the three affected children showing only a mild speech defect. It does not seem too much to

\footnotetext{
* Royal Belfast Hospital for Sick Children, N. Ireland.

$\dagger$ Medical Unit, University College Hospital Medical School, London.

$\ddagger$ Belfast City Hospital, N. Ireland.

$\S$ Royal Victoria Hospital, Belfast.
}

imagine that sooner or later similar metabolic disorders will be discovered that will involve the remaining amino acids.

The present study concerns a further presumed inborn error of amino acid metabolism, this time involving the sulphur-containing compound homocystine. The discovery arose from the submission by one of us (C.M.B.F.) of urine from two mentally retarded sibs whose clinical features were thought to suggest a possible metabolic basis. The urine was sent for examination to others of us (N.A.J.C. and D.W.N.) who were currently running a metabolic screening programme whereby an effort was being made to obtain urine from all the mentally defective children in Northern Ireland. All the urines were being subjected to a series of preliminary routine chemical tests, followed by amino acid paper chromatography, and any other investigations that might seem justified on the basis of preliminary findings. The first report of the preliminary findings in this survey has just been published (Carson and Neill, 1962). About 500 urines had been tested when the specimens from the two sibs above were submitted. These urines gave a strong cyanide nitroprusside reaction for cystine. However, on amino acid paper chromatography the 'cystine' was found to be excreted in moderate quantity by itself and was not accompanied by the basic amino acids (lysine, arginine and ornithine) as always occurs in stone-forming cystinurics (Dent and Rose, 1951), nor by any of the neutral amino acids as in the more generalized aminoacidurias. This in itself favoured the possibility of a more classical type of inborn error with high plasma cystine, the mechanism of excretion being that of an 'overflow', rather than of a 'renal', cystinuria. At this stage (February 1960) the problem was referred to those of us from U.C.H., and samples of plasma and urine were examined there. The urine findings were confirmed, and polaro- 


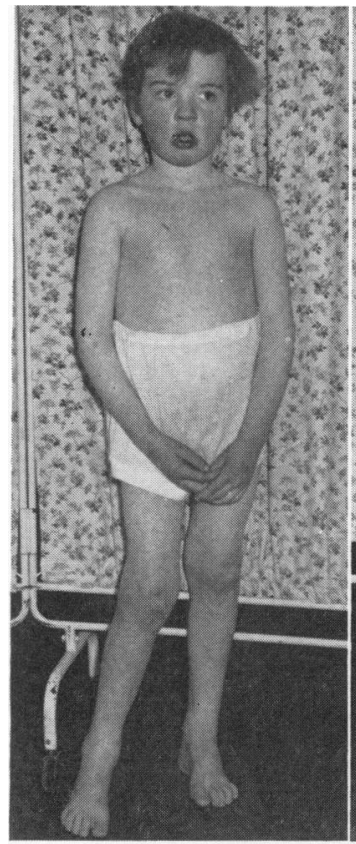

FIG. 1.

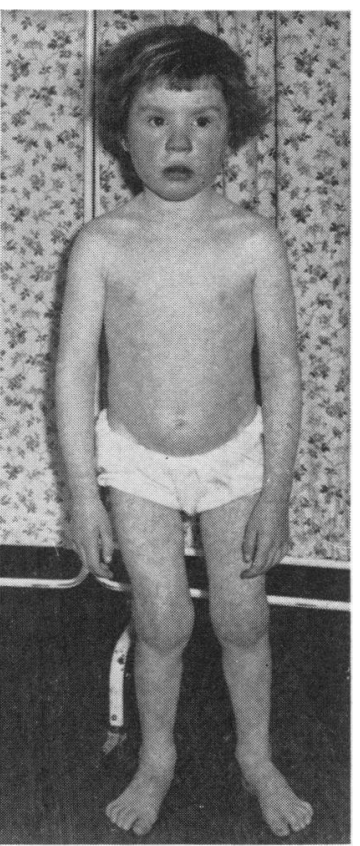

FiG. 2.

FIG. 1.-Patricia B., aged 6 years, in 1960 . Note the slight knock knee and marked mottling of the skin especially on the lower extremities. She has a high red colour to her cheeks which does not show well in the photograph.

FIG. 2.-Pauline B., aged 4 years, younger sister of Patricia whom she resembles closely.

graphic quantitative analyses showed, as expected, raised plasma 'cystine' levels and a normal renal clearance. Further study of the paper chromatograms, however, indicated that the 'cystine' spot was not in the exact position for cystine but in the nearby position occupied by homocystine (Dent, 1948). On the automatic amino acid analyser which had just been constructed, the results were even less ambiguous. The urine elution diagram showed a large peak for homocystine, and the peak for cystine itself, which occupies a clearly separated position, was conspicuous by its absence.

It was decided to proceed further on a joint basis between Belfast and London to identify the abnormal metabolite by proper chemical isolation, to undertake a clinical description of the two affected sibs, and to make a preliminary study of the gross disorder of metabolism which clearly seemed to be responsible for the severe degree of mental deficiency in these children.

A preliminary report of this condition has already been given by Field, Carson, Cusworth, Dent and Neill (1962).

\section{Case Reports}

Patricia B. She was referred to one of us (C.M.B.F.) in December 1959 at the age of 6 years because she had had three convulsive episodes for which no cause could be found. They had occurred at $3 \frac{6}{12}^{\frac{6}{2}}, 4_{12}^{\frac{9}{12}}, 4 \frac{1}{2}$ years, and consisted of several major motor seizures occurring over a period of three to six hours. Following the first fit she was treated with phenobarbitone $(30 \mathrm{mg}$. b.d.), but before the third episode this had been changed to phenytoin sodium (100 mg. nocte) and phenobarbitone (50 mg. b.d.). Since this time she has received no further barbiturates and has had no more fits.

She was the first child, but there had been two previous miscarriages. She was a premature infant of $1,023 \mathrm{~g}$., the prematurity being due to pre-eclamptic toxaemia. She sat up at 10 months and walked at 18 months. At 3 years she was thought to be quite fit, although still slow to develop mentally. Talking began at 5 years.

On examination (Fig. 1) she was rather placid and plump and obviously mentally backward. She was on the $\mathbf{5 0}$ percentile for height and 75 percentile for weight (Harvard School of Public Health chart). She had fine dry sparse blonde hair, and blue eyes showing iridodonesis due to bilateral posterior dislocation of the lenses. Her complexion was fair with bright pink patches of colour on each cheek, her skin elsewhere was covered with erythematous blotches resembling the pattern in erythema ab igne. She had genu valgum and pes cavus. The mouth, teeth, throat, heart and lungs were normal. Her abdomen was protuberant and the liver was easily palpable to three finger breadths below the costal margin, the edge being soft and smooth. The cranial nerves were normal, the reflexes in the arms and abdomen were brisk, and the knee and ankle jerks were increased. The Babinski response was equivocal on the right side and extensor on the left. She was clean and dry in her habits and had about a dozen words of speech. She co-operated well and could obey simple commands. Psychological testing at the age of 7 years 2 months using Columbia Mental Maturity Scale, Wechsler Intelligence tests for children, and revised Stanford-Binet form L (1937) gave a mental age of 2 years 2 months and an I.Q. of 30 . A liver biopsy was carried out and showed 'extensive fatty change but no necrosis or cirrhosis'.

Pauline B. The younger sister of Patricia was brought to hospital by request. She was 4 years old when seen in December 1959. Her birth had been normal and at full term. She had walked at 15 months, was not yet clean and dry and had not yet started to speak. She had had a major motor seizure in July 1959 lasting two hours. Her height was on the 3 percentile and her weight on the 25 percentile. She showed a remarkable resemblance to her sister (Fig. 2), though neither resembled other members of the family, and had the same fine hair, malar flush, iridodonesis, genu valgum, pes cavus, with similar neurological signs. The liver, however, was not palpable. No specific intelligence tests were carried out as her mental capacity was obviously even lower than that of her sister. 


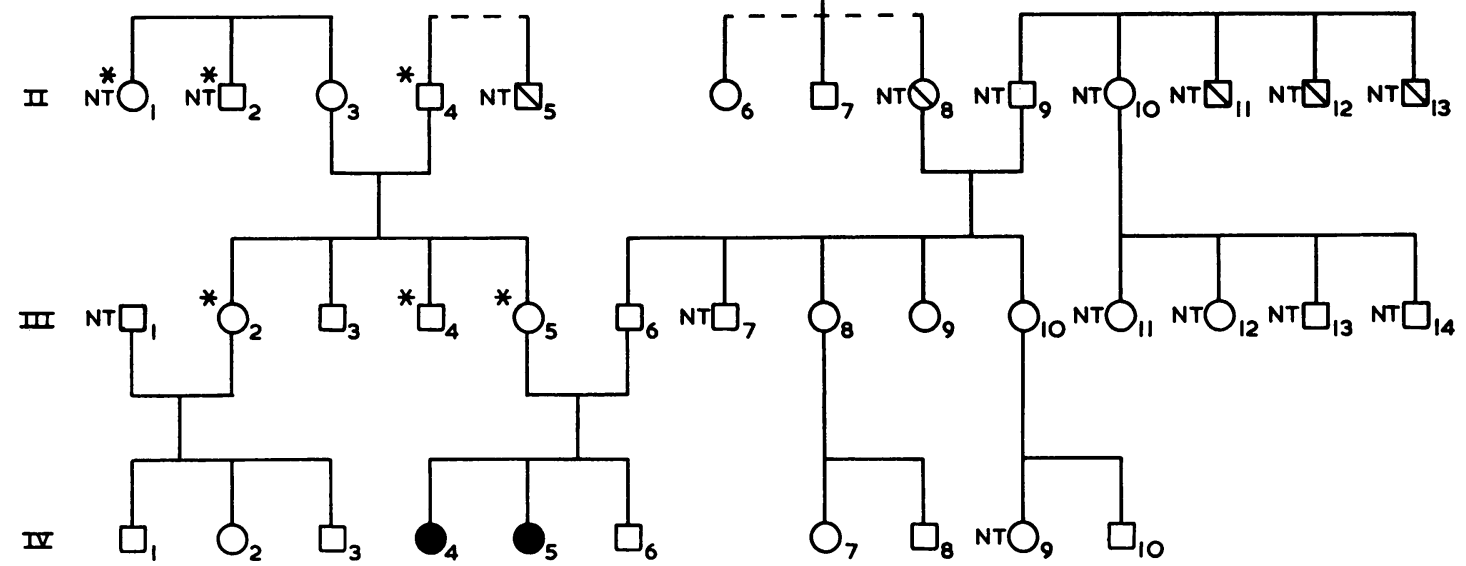

FIG. 3.-Family tree. The two affected sibs (IV 4 and 5) are shown in black. Urine was obtained and analysed from all the subjects except those who have died, or those marked as not tested (NT). Subjects marked * have suffered from schizophrenia. The main mental manifestations in each case were: II 1, auditory hallucinations, restlessness; II 2, visual and auditory hallucinations, persecutory delusions; II 4, auditory hallucinations, delusions, agitation; III 2, auditory hallucinations; III 4, auditory and visual hallucinations; III 5 , auditory hallucinations, paranoia.

At this stage the abnormal urinary amino acid excretion was discovered in Patricia's and Pauline's urine and further routine investigations were carried out on both sibs. Skeletal radiographs, electroencephalogram, electrocardiogram, hearing tests and chromosome studies were normal in both. The ophthalmological report on both children's eyes was 'The lenses are dislocated backwards and slightly upwards. They are completely symmetrical and highly myopic. The fundi are normal.' Microscopic examination of their hair (Dr. A. Jarrett) was normal.

The following investigations were also carried out (Pauline's results quoted first): $\mathrm{Hb} 12.0$ and $9.6 \mathrm{~g} . /$ $100 \mathrm{ml}$; red blood cells 3.86 and 3.08 million; packed cell volume 38 and $29 \%$; mean corpuscular volume 96 and 94 ; mean corpuscular haemoglobin concentration 32 and 34; white blood cells 6,200 and 4,000; plasma $\mathrm{Na} 140$ and $138 \mathrm{mEq} / 1$; $\mathrm{K} 4.6$ and $4.8 \mathrm{mEq} / 1$.; $\mathrm{Cl} 105$ and $102 \mathrm{mEq} / 1$; $\mathrm{HCO}_{3} 18.5$ and $20.0 \mathrm{mEq} / \mathrm{l}$; s serum $\mathrm{Ca} 10.3$ and $9.8 \mathrm{mg} . / 100 \mathrm{ml}$.; $\mathbf{P}$ (Patricia only) $5.0 \mathrm{mg} . / 100 \mathrm{ml}$.; plasma specific gravity 1.025 and 1.025 ; plasma total protein $6.75 \mathrm{~g}$. and 6.2 g./100 ml.; electrophoresis showed reduced level of $\alpha$-globulin; plasma alkaline phosphatase $17 \cdot 0$ and 15.4 K.-A. units; serum bilirubin 0.1 and $0.3 \mathrm{mg} . / 100 \mathrm{ml}$.; thymol turbidity (Patricia only) 1 unit; S.G.O.T. 28 and 25; S.G.P.T. 12 and 15; serum leucine aminopeptidase (L.A.P.) 300, 220 and 160, 213; isocitric dehydrogenase (I.C.D.) 750,710 and 640 ; routine urine microscopy and culture was normal. While most of these findings are within normal limits, it is perhaps of note that the L.A.P. and I.C.D. levels were raised. These enzymes have been particularly inculpated in diseases of the liver (Harkness, Roper, Durant and Miller, 1960; Bressler, Forsyth and Klatskin, 1960; Sterkel, Spencer, Wolfson and Williams-Ashman, 1958).

Family Studies. A family tree of the near relatives of Pauline and Patricia B. is shown in Fig. 3. Their parents were not consanguineous and as far as questioning could elicit there were no exactly similar children, nor any others with mental retardation. Of especial interest was the youngest child of the sibship, Kevin, who was then aged $1 \frac{1}{2}$ years and who appeared mentally normal and physically quite unlike Pauline and Patricia. Mrs. B., the mother, was a housewife of 32 years, who enjoyed good general health and looked after the family well in conditions of some poverty. Mr. B., the father, age 35 years, was in England working and was healthy. Of note was the very high incidence of schizophrenia on the mother's side of the family, the mother herself although well till that time has subsequently had to be admitted to hospital for psychiatric supervision. The legend to Fig. 3 quotes the main psychiatric symptoms. Urine was also obtained from as many as possible of the near relatives, and analysed by amino acid chromatography. No abnormalities were found.

Therapeutic Trial with Oral Cystine. Our first theory of the pathogenesis of the disease was that it was due to a cystine deficiency resulting from a metabolic block in the breakdown of methionine and homocystine. We thought that the friable sparse hair in both sibs provided clinical evidence supporting this theory, since this situation is readily produced experimentally in animals on suitably deficient diets. The brain damage in the 


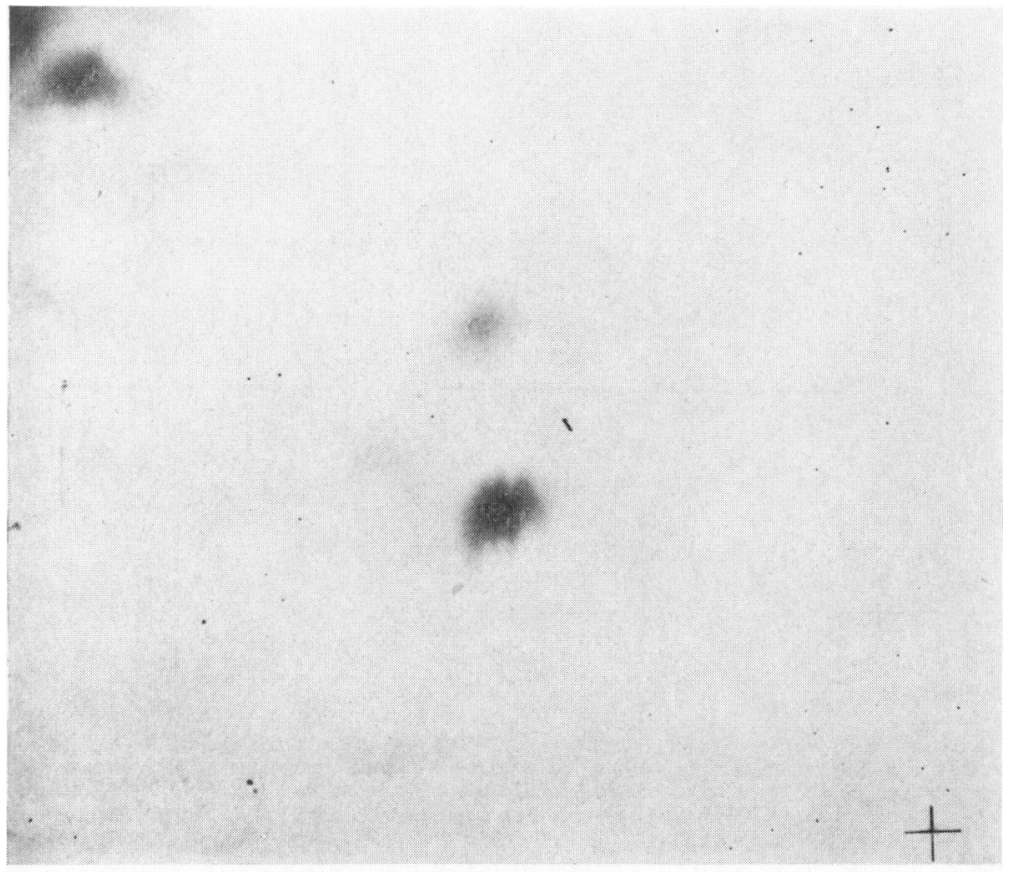

Fig. 4.-Standard urine amino acid chromatograms of Pauline B. (a) Urine untreated, showing spots of glycine, taurine and in the top left corner added marker. (b) Urine after oxidation. Notice the appearance of homocysteic acid from oxidation of the homocystine which otherwise decomposes on the chromatogram. The central glycine spot has been partly destroyed. (c) Oxidized urine with cysteic acid added as marker. The cysteic acid is the upper of the two right spots. After homocysteic acid is added it moves exactly to the position occupied by the lower of the two right spots.

FIG. 4 (a)

FIG. 4 (b)

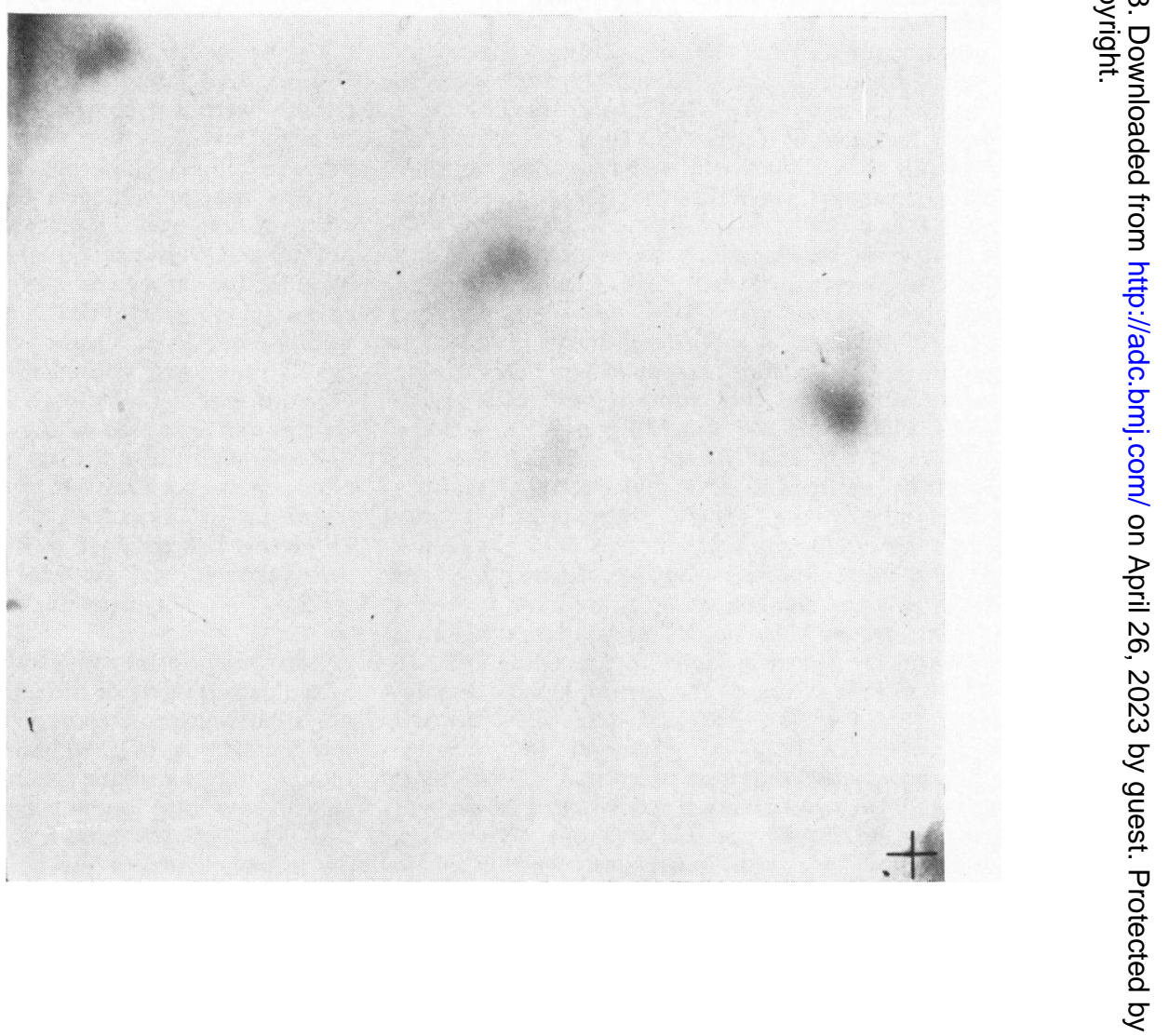




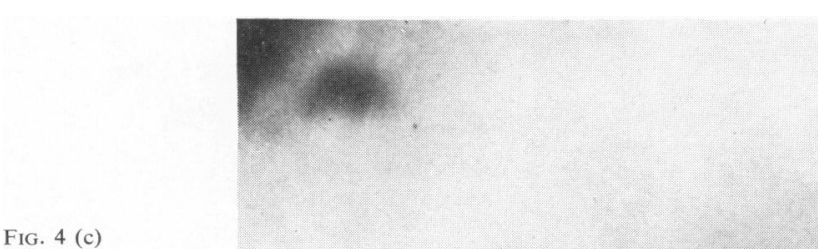

affected sibs would presumably by now be irreversible, but we thought that by feeding a large dose of extra cystine to the younger of the two sibs (Pauline) on a long-term basis, we might obtain evidence as to a state of deficiency or otherwise. We sought, in particular, evidence for any growth spurt, for improvement in hair growth, and any possible behaviour changes. Mrs. B. agreed to leave the older sib (Patricia) to act as a control subject.

Pauline began to take cystine, in $1 \mathrm{~g}$. tablets, at a dose of 1 g. t.d.s. in April 1961. For the first two months Mrs. B. was most pleased with the treatment, a small weight gain occurring, the child appearing livelier and happier. After two months, however, following a bad cold and mild fever she was brought to hospital with paralysis of the left leg following a presumed fit. Slow return of function occurred in the next weeks, but she remained with a dropped foot on the left. The cystine was not stopped then but was stopped after six months when fits recurred. After two and a half months off cystine it was given again in full dosage for another three and a half months. Review of our total data and charts unfortunately does not allow any favourable conclusion to be drawn from the treatment trial. There was no growth spurt. Hair did not change dramatically, but two observers thought that its appearance and characteristics were improved. Her behaviour improved during the first two months but this was not maintained. She developed increasing spasticity and increasing difficulty in walking but it is our view that this was part of the spontaneously developing disease process and not related to the cystine or to her fits. Pauline now has extensor plantar responses on both sides and very exaggerated knee and ankle jerks. Although Patricia received no cystine supplement she too has slowly increasing spasticity with exaggerated reflexes in her legs and remains with an extensor plantar response on the left side.

\section{Methods}

Paper Chromatography. The chromatographic methods used in Belfast have been described by Carson and Neill (1962). Subsequent work in London was done by the technique of Dent (1948). All urine specimens from each of the affected sibs constantly gave a moderately strong cyanide nitroprusside test for cystine (Brand, Harris and Biloon, 1930) and a strong spot on the chromatograms of the oxidized urines in the region of cysteic acid (Fig. 4), otherwise the amino acid excretion pattern was normal and in particular there was no excess excretion of the basic amino acids. Careful matching with pure cysteic acid showed that the sub- 

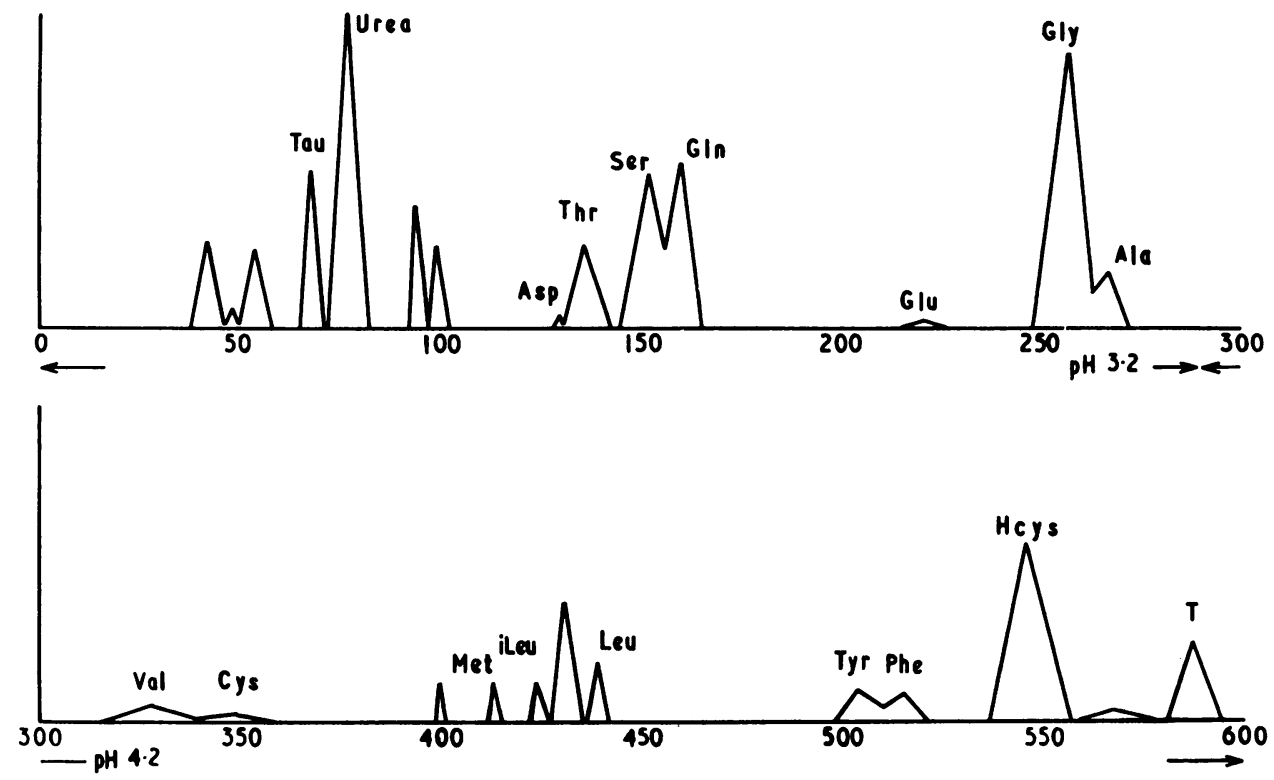

FIG. 5.-Elution diagram of the amino acids in the urine of Pauline B. obtained by the Moore and Stein technique. Hcys = homocystine. The unmarked peak between isoleucine and leucine is that of the mixed disulphide of cystine and homocystine.

stance in the patient's urine migrated to a slightly different position, indeed to a position marked on our reference map (Dent, 1948) as that occupied by homocysteic acid. Addition of homocysteic acid showed exact correspondence with the urine spot (Fig. 4). The strength of the spot suggested that the daily output of homocystine was much less than that of cystine in cystinuria (500-1,000 mg./day) and very much less than that of argininosuccinic acid in argininosuccinic aciduria (3,000 mg./day). Chromatograms of urine from most of the near relatives were also carried out. All were quite normal.

Polarography. Measurements were made (by Miss Helen Green) on fasting plasma and urine before it was suspected that the substance was not cystine. The catalytic wave method (Reed, 1942) was used with a Tinsley Industrial recording polarograph. Good waves were obtained and results in terms of 'cystine' were: plasma $1.2 \mathrm{mg} . / 100 \mathrm{ml}$. and urine (three-hour collection) $55 \mu \mathrm{g} . / \mathrm{min}$. corresponding to a 24-hour excretion of $80 \mathrm{mg}$. and a clearance $\frac{(\mathrm{Uv})}{\mathrm{P}}$ of $4.6 \mathrm{ml} . / \mathrm{min}$.

Quantitative Ion-exchange Chromatography. Most of the analyses were done on specimens from Patricia B. Sufficient specimens were obtained from Pauline to confirm that she had the same biochemical abnormality.

An automatic amino acid analyser was used. It was built in the Medical Unit, University College Hospital Medical School, after the design of Spackman, Stein and Moore (1958). The first analyses of urine were incom- plete. The eluate from the column at that time could only be analysed as far as the cystine peak. The analyses, however, did show that the increased output of cystine expected from the original paper chromatograms and polarography was not present. After the paper chromatographic identification of the homocystine had been made we were able to carry out a complete column analysis. This showed the presence of a large peak in the homocystine position, confirmed by addition of pure 1-homocystine to the urine (Fig. 5). The excretion of homocystine was about $50 \mu \mathrm{g} . / \mathrm{min}$. (72 $\mathrm{mg} . / 24 \mathrm{hr}$.) and was grossly abnormal as no homocystine is detectable in a similar analysis of normal urine. The elution diagrams also showed the presence of a moderate-sized peak in the position occupied by the mixed disulphide derived from half cystine and half homocystine. This compound has been identified in the urine of cystinurics (Frimpter, 1961), but is not yet reported from other sources. Its excretion rate in the two sibs was $10-30 \mu \mathrm{g} . / \mathrm{min}$. (14-42 mg./24 hr.), which can be compared with the 40-100 $\mathrm{mg}$./day in cystinuric urine.

Specimens were then obtained of timed urines (approximately 3 hours) with approximately midpoint blood, so as to enable amino acid clearance determinations to be carried out. The urine and separated plasma were frozen and transported in this state to London where they were kept frozen $\left(-10^{\circ} \mathrm{C}\right.$.) till the time of analysis. The results (not quoted here) for the non-sulphur containing amino acids were all within normal limits. With regard to the cystine, the urine excretion was low (not more than $1 \mu \mathrm{g} . / \mathrm{min}$., normal 5-10 $\mu \mathrm{g} . / \mathrm{min}$. ), homocystine excretion being similar to the previously obtained 
figure. Rather unexpectedly no plasma cystine or homocystine was detected. We were a little slow to realize that the reason for this was the occurrence of a storage artefact, since in the presence of the plasma protein both cystine and homocystine slowly combine with the protein. They are lost unless the protein precipitation is carried out immediately after the blood has been obtained (Stein and Moore, 1954; Eagle, Oyama and Piez, 1960). Analysis of specially obtained fresh plasma showed cystine levels of $0.6 \mathrm{mg} . / 100 \mathrm{ml}$., a low normal result, and there was a good homocystine peak giving a level of $1.5 \mathrm{mg} . / 100 \mathrm{ml}$. (homocystine is undetectable in normal plasma). A calculation of homocystine clearance on the basis of the latter figure gave a result of $3.3 \mathrm{ml} . / \mathrm{min}$. (uncorrected). Of potential significance was the plasma methionine level which on three occasions gave figures of $1 \cdot 7,1 \cdot 1$ and $0.7 \mathrm{mg} . /$ $100 \mathrm{ml}$. (normal 0.3-0.6 mg. $/ 100 \mathrm{ml}$.). There was no corresponding increase in methionine excretion presumably because the renal clearance is normally so very low. No mixed disulphide was detected in the fresh or stored plasma.

Isolation and Characterization of Homocystine. Although the paper and column chromatographic methods of identifying the homocystine were fairly convincing, final confirmation by classical chemical methods seemed advisable, especially as the chromatographic methods could give no data on optical rotation.

Preliminary attempts to isolate the homocystine by crystallization from concentrated urine failed, in spite of the considerable insolubility of the compound. The next method tried was that of displacement chromatography from an ion-exchange resin column as previously used for isolating urinary ampholytes (Westall, 1955). This was also unsuccessful, the insolubility of the homocystine being the probable reason. Fortunately, however, homocystine had given a discrete peak on the flow sheet of the automatic amino acid analyser, no crystallization occurring with the much more dilute solutions used in this method. We therefore next attempted its isolation by elution chromatography using a much larger ion-exchange column with volatile buffers for elution in the way already described by Hirs, Moore and Stein (1952).

Amberlite resin $2 \mathrm{~kg}$. CG 120, type III 400 mesh was suspended in water and decanted several times to remove the very fine material. The resin was then treated with 101 . of $2 \mathrm{~N}-\mathrm{NaOH}$, washed with water by repeated decantation to remove the excess $\mathrm{NaOH}$ and then treated with 51 . of $4 \mathrm{~N}-\mathrm{HCl}$. By further washing, the excess $\mathrm{HCl}$ was removed and the resin was converted to the $\mathrm{NH}_{4}$ form by the addition of 101 . of $3 \mathrm{~N}-\mathrm{NH}_{4} \mathrm{OH}$. The resin was then washed with distilled water, at first by decantation and finally by filtration on a Buchner funnel. The resin cake was then suspended in $0.2 \mathrm{M}$ ammonium acetate buffer at $p \mathrm{H} 4.5$ and was ready for packing in the column. The column consisted of a standard Pyrex glass pipeline section 30 in. $(76 \cdot 2 \mathrm{~cm}$.) long and $2 \frac{1}{2}$ in. $(6 \cdot 35 \mathrm{~cm}$.) wide with flanged ends. End plates were fitted to carry an inlet tube at the top end and a glass wool filter bed and an exit tube at the bottom end (Westall, 1961). The column was filled with the prepared resin to a height of $23 \mathrm{in} .(58.4 \mathrm{~cm}$.) allowing a head space of $1-2$ in. $(2 \cdot 5-5 \mathrm{~cm}$.) of buffer. The exit tube was connected to an automatic fraction collector set to collect fractions $(50-60 \mathrm{ml}$. each) at 20 -minute intervals.

$250 \mathrm{ml}$. of the patient's urine was acidified with $\mathrm{HCl}$ to $p \mathrm{H} 3$ and was shaken for two hours with $20 \mathrm{~g}$. acetic acid activated charcoal (Partridge, 1949). The charcoal was removed by filtration and the filtrate was passed through the resin column. The urinary amino acids, which were retained by the resin, were eluted with about 51 . of $0.2 \mathrm{M}$ ammonium acetate buffer at $p \mathrm{H} \mathrm{4.5}$. $2 \mathrm{ml}$. aliquots of the collected fractions $(55 \mathrm{ml}$. each) were treated with $1 \mathrm{ml}$. of $5 \%$ sodium cyanide, allowed to stand for 15 minutes and then mixed with $0.5 \mathrm{ml}$. of $1 \%$ sodium nitroprusside. The typical bright pinkish red colour indicated those fractions which contained cystine or homocystine. Fractions 21-24 contained cystine and fractions $75-80$ contained the homocystine. Fractions $75-80$ were combined $(350 \mathrm{ml}$.) and transferred to a one-litre flask. They were then reduced to a syrup by evaporation in vacuo. The thin syrup was transferred to a $250-\mathrm{ml}$. flask fitted with a cold-finger condenser. The flask was immersed in a water bath at $50^{\circ} \mathrm{C}$. and evacuated for several hours to complete the sublimation of the ammonium acetate. A pale cream coloured residue remained: yield $47 \mathrm{mg}$.

This procedure was repeated with two further samples of $250 \mathrm{ml}$. of the patient's urine which gave a total yield of crude homocystine of $155 \mathrm{mg}$. Recrystallization was carried out from dilute $\mathrm{NH}_{4} \mathrm{OH}$ by allowing the solution to stand in a desiccator over $\mathrm{H}_{2} \mathrm{SO}_{4}$. Crystals were deposited slowly as the free $\mathrm{NH}_{3}$ from the solution was absorbed by the $\mathrm{H}_{2} \mathrm{SO}_{4}$. Yield crop (1) $76 \mathrm{mg}$. Found: C $35 \cdot 7 ; \mathrm{H} 5 \cdot 6 ; \mathrm{N} 10 \cdot 6 ; \mathrm{S} \mathrm{23.9 \%} ; \mathrm{C}_{8} \mathrm{H}_{16} \mathrm{O}_{4} \mathrm{~N}_{2} \mathrm{~S}_{2}$ requires

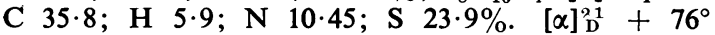
(C, $1 \cdot 1 \%$ in $\mathrm{N} \mathrm{HCl}$ ).

The isolated material gave only one spot when oxidized and run on paper chromatography, which corresponded with the position taken up by authentic L-homocysteic acid. Similarly, it was eluted as a single peak in the same position as L-homocystine when run on the automatic amino acid analyser.

Methionine Loading Tests. In order to investigate a possible block in the breakdown of methionine, measurements of amino acid concentrations in body fluids were made after an oral load of L-methionine. These were carried out on the two affected sibs, the apparently normal sib (Kevin), the mother, and on two normal adult males acting as controls. All the tests followed the general pattern described for amino acid clearance measurements by Cusworth and Dent (1960). After an overnight fast, water was given to drink ad lib., and an accurately timed, spontaneously voided urine of approximately one-hour duration was collected. An oral loading dose of $\mathrm{L}$-methionine was then given in a dosage of $100 \mathrm{mg} . / \mathrm{kg}$. body weight suspended in fruit cordial (except for Kevin who received $75 \mathrm{mg} . / \mathrm{kg}$.). Further 
TABLE 1

PLASMA METHIONINE LEVELS (mg./100 ml.) BEFORE AND AFTER ORAL METHIONINE

\begin{tabular}{|c|c|c|c|c|c|}
\hline & ! & \multirow{2}{*}{ Fasting } & \multicolumn{3}{|c|}{ Minutes After Oral Methionine } \\
\hline & & & 30 & 90 & 150 \\
\hline $\begin{array}{l}\text { Mrs. B. (1) .. } \\
\text { (2) } . \dot{ } \\
\text { Normal } \\
\text { (D.G.) }\end{array}$ & $\begin{array}{l}\cdots \\
\cdots \\
\cdots \\
\cdots\end{array}$ & $\begin{array}{l}0.33 \\
0 \cdot 36 \\
0 \cdot 24 \\
0.42\end{array}$ & $\begin{array}{l}10 \cdot 4 \\
14 \cdot 4 \\
12 \cdot 5 \\
12 \cdot 5\end{array}$ & $\begin{array}{l}20 \cdot 3 \\
14 \cdot 6 \\
10 \cdot 2 \\
10 \cdot 0\end{array}$ & $\begin{array}{l}12 \cdot 2 \\
11 \cdot 3 \\
10 \cdot 1\end{array}$ \\
\hline
\end{tabular}

consecutive urines at intervals of about one hour were then collected for the next three hours. In the adults, blood samples were taken immediately before the methionine load was given, and at half, one and a half and (except in one normal) two and a half hours after, and in the test on Patricia immediately before and one and a half hours after the methionine. In the younger children, Pauline and Kevin, the timing of the urine collections had to be more flexible and no blood samples were taken. Plasma and urine samples, frozen as soon as possible and then transported to London, were later analysed on the automatic amino acid analyser as described above. Urine creatinine was determined by the method of Bonsnes and Taussky (1945).

In all the tests no marked or consistent changes were

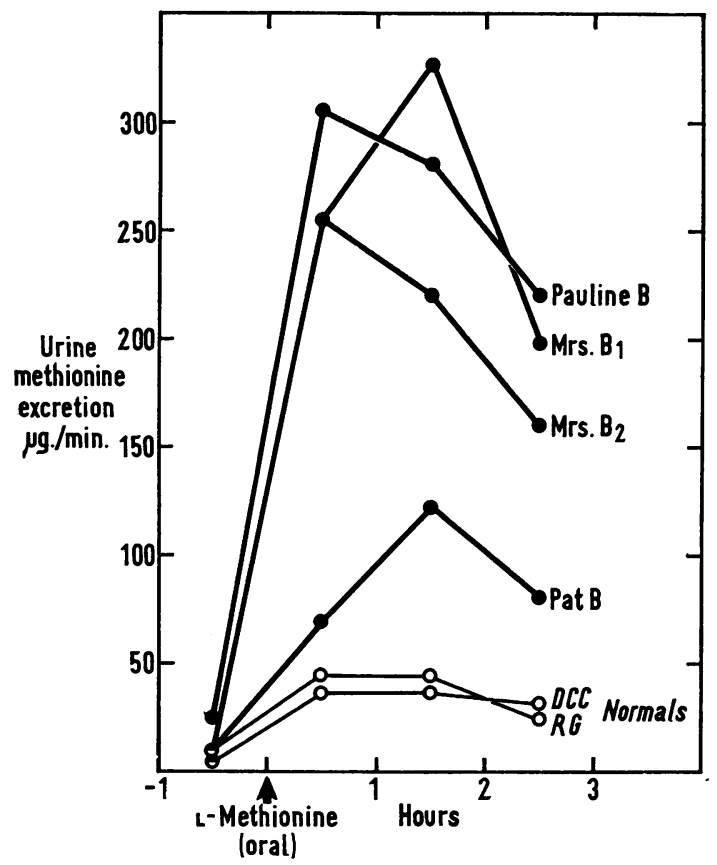

FIG. 6.-Urinary excretion of methionine after oral methionine feeds. The first two values from the two separate feeds of Mrs. B. were identical, so are shown on the graph superimposed. Note the very marked abnormality of methionine excretion shown by both the affected sibs and by their mother who presumably is a heterozygote, the sibs being homozygotes.
TABLE 2

METHIONINE CLEARANCES

(ml./min. uncorrected)

\begin{tabular}{|c|c|c|c|c|c|}
\hline & & \multirow{2}{*}{ Fasting } & \multicolumn{3}{|c|}{ Hours After Oral Methionine } \\
\hline & & & $0-1$ & $1-2$ & $2-3$ \\
\hline $\begin{aligned} & \text { Mrs. B. }(1, . \\
& \text { (2) } \\
& \text { Normal }(\mathrm{D} . \dot{C} .) \\
&(\text { R.G.) }\end{aligned}$ & $\begin{array}{l}\cdots \\
\cdots \\
\cdots\end{array}$ & $\begin{array}{l}1 \cdot 3 \\
(\overline{1 \cdot 3}) \\
(2 \cdot 1)\end{array}$ & $\begin{array}{l}2 \cdot 5 \\
1 \cdot 8 \\
0 \cdot 29 \\
0 \cdot 35\end{array}$ & $\begin{array}{l}1 \cdot 6 \\
1 \cdot 5 \\
0 \cdot 37 \\
0 \cdot 44\end{array}$ & $\begin{array}{l}1 \cdot 6 \\
1 \cdot 4 \\
\overline{0 \cdot 24}\end{array}$ \\
\hline
\end{tabular}

seen in the non-sulphur-containing amino acids in the specimens before and after the methionine load, and these figures will not be given here. No change in plasma level or excretion of cystine was seen in any of the subjects, as might have been predicted from the observations on normal subjects of Dent, Senior and Walshe (1954).

The results for methionine and homocystine are given in Tables 1 and 2 and in Figs. 6 and 7.

In the normal subjects the fasting clearances are shown in brackets, as the fasting methionine excretions and hence the clearances which are calculated from them are almost certainly an overestimate due to the difficulty of measuring accurately the very small methionine peak among a number of small known and unknown peaks which occur in this part of the chromatogram (Moore,

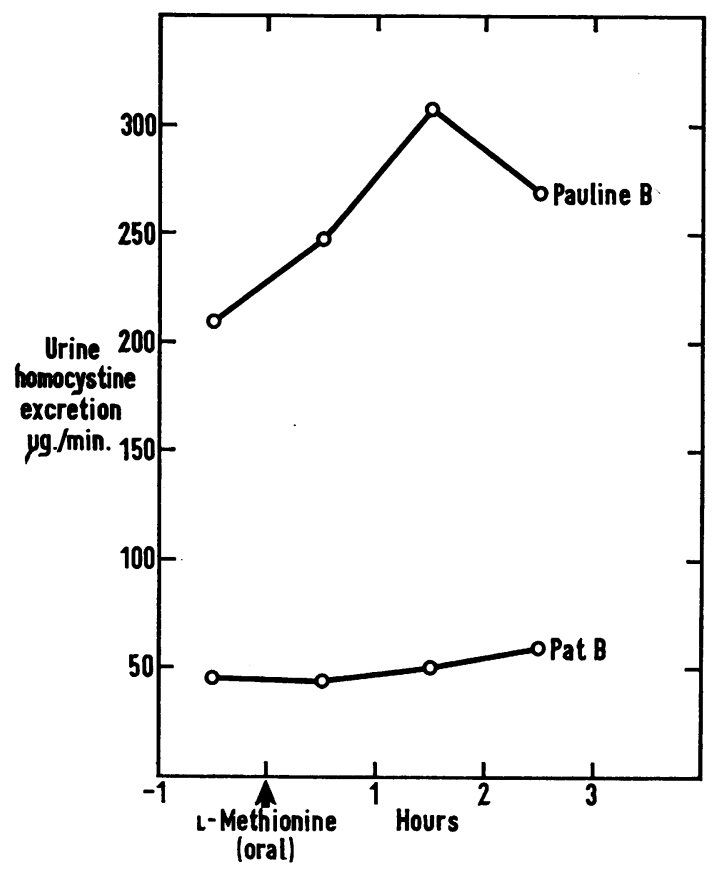

FIG. 7.-Urinary excretion of homocystine after oral methionine loads. Note the surprisingly small change observed. Patricia's output of homocystine was exceptionally low on this occasion for reasons not understood. Her basal excretion of homocystine is usually similar to that of Pauline. 
Spackman and Stein, 1958; Frimpter and Bass, 1962). In one normal subject, no peak was seen in the homocystine position in the fasting or first-hour urines; in the second- and third-hour urines there was a slight deflection of the baseline of the elution diagram in the homocystine position amounting at the most to $2 \mu \mathrm{g}$./ min. In the other normal subject a very small peak was seen in this position in the fasting urine specimen amounting to about $5 \mu \mathrm{g}$./min. and falling slowly during the test to about $1 \mu \mathrm{g} . / \mathrm{min}$.; it seems highly probable that this was in fact not homocystine at all but $\beta$-alanine which occupies the same position on the elution diagram.

Mrs. B. was examined on two occasions, the first when she was in good health and the second during her admission to hospital for psychiatric reasons. Following the oral methionine her plasma level showed a higher and possibly delayed rise compared with the normal subjects. Her methionine excretion was conspicuously abnormal, being five to eight times greater than in our control subjects, the renal clearances also being about five times higher. No homocystine was seen in the fasting urines, but a small but definite peak was seen in the second- and third-hour urines on both occasions, amounting to $6 \mu \mathrm{g} . / \mathrm{min}$. on the first occasion and $12 \mu \mathrm{g} . / \mathrm{min}$. on the second.

We were surprised at the relatively small basal excretion of homocystine by Patricia on the occasion of the methionine load test and at its failure to increase following the load. On previous occasions (see above under 'Polarography' and 'Quantitative ion-exchange chromatography') when fasting timed urines had been collected, her homocystine excretion had been comparable to that shown on this occasion by her younger sister Pauline. It is emphasized that the normal subjects showed no detectable homocystine excretion. When allowance is made for their body sizes, both children showed a much greater excretion of methionine than the control adults, indeed their handling of methionine resembled closely that of their mother.

Kevin B. showed a fasting methionine excretion, corrected for his surface area of $0.6 \mathrm{~m} .^{2}$, of $2 \mu \mathrm{g} . / \mathrm{min}$. which increased to 75 and $127 \mu \mathrm{g}$. $/ \mathrm{min}$. during the first and second hours following a methionine load of $75 \mathrm{mg}$./ kg. No change was observed in the very small deviation of the baseline in the homocystine position.

Amino Acid Analysis of Hair. It seemed possible that the abnormal hair in the affected sibs was due to the incorporation into the hair molecule of some homocystine in place of cystine. A less likely alternative was, that of the two amino acids, the hair contained cystine only but in smaller quantity than normal.

Samples of hair from Patricia and Pauline were cut into pieces about $1 \mathrm{~mm}$. in length, washed several times with chloroform and dried to constant weight at $110^{\circ} \mathrm{C}$. and then hydrolysed by refluxing with $6 \mathrm{~N}-\mathrm{HCl}$ for six hours. Examination of samples of the hydrolysates from both children on the automatic amino acid analyser showed the presence of a large amount of cystine, but no homocystine was detected. A further hair sample from Patricia was washed and dried in a similar manner, but the hair was oxidized with performic acid (Schram, Moore and Bigwood, 1954) before hydrolysis for 20 hours, so that an accurate quantitation could be obtained (unoxidized cystine decomposes somewhat during acid hydrolysis). Analysis showed a cystine content of $16.6 \mathrm{mg} . / 100 \mathrm{mg}$. dry hair, within the normal range for human hair.

\section{Discussion}

We have presented evidence that the two mentally retarded sibs have a gross metabolic disorder involving the sulphur-containing amino acids, and that this is very likely to be the immediate cause of all their abnormal clinical manifestations. In brief the clinical features comprise mental retardation, iridodonesis and red mottling of the skin. There is evidence of a progressive paraplegia and perhaps of increasing liver involvement. These features, together with their general appearance (Figs. 1 and 2) are sufficiently characteristic for the condition to be easily recognizable in future; it is indeed as characteristic in its own way as is the picture in mongolism. Moreover, the urine test, involving the same cyanide nitroprusside reaction as used for cystine, is very easy to perform on a mass production basis. A search for further cases should not therefore be too difficult. One of us (N.A.J.C.) has already discovered six more cases in Northern Ireland, and Dr. G. Komrower and Miss V. K. Wilson (personal communication) have found one in Manchester, so there is the possibility that this disease is not too rare. The way the discovery was made is of some interest. Urine from the sibs was submitted for examination on account of their unusual clinical features. However, the routine survey already in operation was partly the stimulus for the submission and in any case would presumably have caught up with the children sooner or later. Many such metabolic screening programmes are under way in other medical centres and it seems that they can be rewarding so long as one is not too quickly disappointed by the large numbers of negative findings. We do not expect patients with homocystinuria to present with urinary calculus. Homocystine is very insoluble, but the daily excretion is probably just below the threshold for stone formation, if comparison with cystine calculus is valid (Dent and Senior, 1955).

Our loading tests with L-methionine were aimed to uncover, if possible, the actual site of the presumed metabolic block in homocystine metabolism. The broad lines of the normal metabolic pathway by which methionine is converted to cystine have been well worked out and are summarized in Fig. 8.

It is important to note that it is homocysteine, not homocystine (the oxidized corresponding -S-S- 

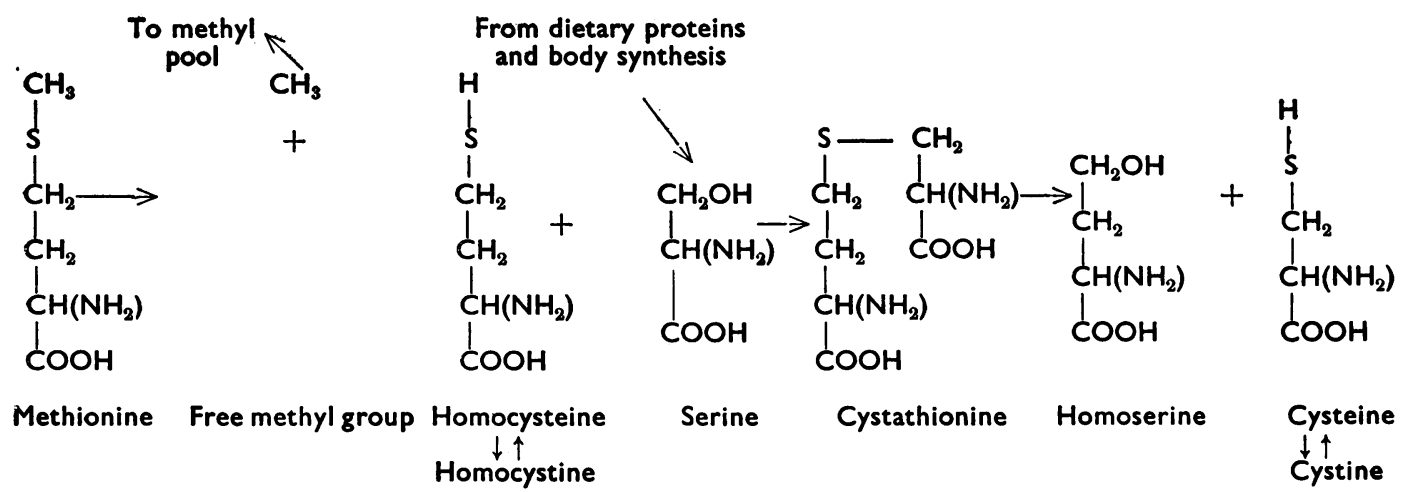

FIG. 8.-Normal metabolism pathway by which methionine is converted to cystine.

compound) that arises in the direct metabolic sequence during the formation of cystine from methionine. Nevertheless, it seemed likely at first that an enzymic dysfunction between homocysteine and cystathionine could produce an accumulation of homocysteine which, depending on its state of equilibrium with homocystine and other factors, might manifest itself more readily as an overproduction and excess excretion of homocystine. With such a simple mechanism an oral load of 1-methionine should quickly produce a large increase in homocystine excretion. We were at first surprised when we noted that this did not happen (Fig. 7). However, further consideration of the data has led us to appreciate the possible significance of the quantity of the daily excretion of homocystine. This varied from 50-100 mg. a day, a quantity much less than would be expected if the main bulk of the daily intake of methionine (1-2 g.) was excreted in this form. A complete metabolic block, therefore, as occurs in phenylketonuria, seems most unlikely. Indeed a true metabolic block in the metabolism of the sulphur amino acids does seem to occur in cystathioninuria, presumably at the point between cystathionine and homoserine in the diagram (Fig. 8). In this condition the daily excretion of the corresponding sulphur compound was $500 \mathrm{mg}$. (Harris et al., 1959), and it was shown to be considerably raised on feeding extra methionine. We need to know a lot more about the metabolism of sulphur compounds before settling the problem posed by the homocystinuria in our sibs. Obvious possibilities are a disorder of oxidation reduction potentials in the cell whereby a proportion of the homocysteine formed in a normally functioning sequence from methionine to cystine is oxidized to homocystine and then trapped in this form and excreted. An enzyme able to perform this step has been found in rat liver by Racker (1955), and an equivalent mechanism may well occur as an explanation for the excess cystine formation in cystinosis. Another possibility is that the disorder involves another step in homocysteine metabolism, such as its metabolism to $\alpha$-amino butyric acid by the enzyme homocysteine desulphhydrase (Fromageot and Desnuelle, 1942). The immediate impression, however, from our methionine loading experiments suggests something quite different, namely, an inability of the body cells in general to take up and metabolize the fed methionine, and of the renal tubular cells in particular to reabsorb methionine normally from the glomerular ultrafiltrate. This looks more like a defective generalized cellular transport mechanism for methionine, but if so, the reason for the overproduction and consequent excretion of homocystine seems obscure. Perhaps methionine and homocysteine share the same transport mechanism, defective in our patients.

More evidence is required from family studies before homocystinuria can be definitely classified as an inborn error of metabolism. The existence of a gross and identical disorder of metabolism in two sibs, the rest of the family appearing relatively normal, is strong evidence in favour of such an inborn error, presumably inherited as a recessive characteristic. The lesser abnormality of methionine tolerance found in the mother is evidence in favour of her being heterozygous for a gene found in homozygous form in the two affected sibs. It should be added here that there was a clear clinical difference between the two sibs, the older one Pauline having a large liver shown to be fatty on biopsy and showing minimal biochemical signs of dysfunction. There is a suggestion here that with time the disease may ordinarily progress to this stage and perhaps later develop into a true cirrhosis.

It is a happy feature of the discovery of this type of biochemical disorder that soon afterwards 
we can usually begin to devise fairly plausible forms of treatment. Our first guess was that a block somewhere in the sequence from methionine to cystine would make the subject dependent entirely on dietary cystine for normal metabolic requirements. In other words in our two sibs cystine had become an essential amino acid, rather as tyrosine is in a phenylketonuric. Such children might well suffer from some degree of cystine deficiency, especially in infancy should their diet be largely of cows' milk, in which most of the protein sulphur is as methionine $(70 \%)$ rather than as cystine $(30 \%)$. However, in human milk the situation is reversed, $60 \%$ of the protein sulphur being as cystine (Soupart, Moore and Bigwood, 1954). Hence a simple cystine supplement might suffice to prevent the development of the disease, especially if the diagnosis can be made soon after birth before irreversible consequences have time to develop. It seemed clearly too late to expect any improvement in mental status in our sibs, so a trial was done on one of them giving extra cystine by mouth and hoping for a growth spurt or other clinical signs of improvement. Nothing happened, however. This does not surprise us so much now that we realize that our simple concept of the metabolic block requires modification. If a defect of methionine transport mechanisms is involved we might even argue that additional methionine rather than cystine would be the treatment and that the fatty liver of the elder sib was the consequence of a methyl group deficiency from an inability to demethylate methionine in adequate quantity. Supplementations of this kind on affected growing children would be better assessed if they could be carried out while simultaneous nitrogen balances were being performed. Further experiments along classical lines to determine their actual dietary requirements of methionine and of cystine also appear to be well worth carrying out.

\section{Summary}

Arising from a biochemical survey of urines from mental defectives in Northern Ireland it has been revealed that two sibs with a rather characteristic clinical appearance constantly excrete moderate quantities of an amino acid reacting like cystine to the cyanide nitroprusside test.

The abnormal amino acid has been identified by chromatographic and classical chemical methods as L-homocystine. The mechanism of the urinary excretion is an 'overflow' one.

Loading tests with L-methionine have been done on the mother, the two affected sibs and on the normal sib. The results have been most difficult to interpret. The affected sibs and the mother show a slightly reduced ability to metabolize methionine, and a much larger than expected urinary methionine excretion, indicating high renal clearances. Homocystine excretion, surprisingly, only increased a little after the methionine load.

We assume that there is an inborn error of metabolism here, the detailed mechanism remaining obscure. We suggest the name 'homocystinuria' for the disease.

Preliminary trials have begun of treatment by additional oral cystine. Our first hypothesis was that the immediate cause of the disease might be a cystine deficiency due to an error of metabolism that prevents the normal conversion of methionine into cystine and that also manifests itself by the accumulation and excretion of excessive quantities of the closely related compound homocystine. We are having difficulties, however, in confirming this. An alternative hypothesis is that a defect in methionine transport systems is the primary cause.

We thank Miss E. Davies and Miss J. Tindley for help with the column chromatography. The amino acid analyser was built by Mr. C. E. Glover and Mr. G. Marshall with the aid of a generous grant from the Ames Co. Inc. One of us (D.C.C.) was supported by a Fellowship from the Mental Health Research Fund, another (N.A.J.C.) was in receipt of a research grant from the Hospital Committee of the Royal Belfast Hospital for Sick Children.

\section{REFERENCES}

Allan, J. D., Cusworth, D. C., Dent, C. E. and Wilson, V. K. (1958). A disease, probably hereditary, characterised by severe mental deficiency and a constant gross abnormality of aminoacid metabolism. Lancet, 1, 182.

Auerbach, V. H., Di George, A. M., Baldridge, R. C., Tourtellotte, C. D. and Brigham, M. P. (1962). Histidinemia. J. Pediat., $60,487$.

Baron, D. N., Dent, C. E., Harris, H., Hart, E. W. and Jepson, J. B. (1956). Hereditary pellagra-like skin rash with temporary cerebellar ataxia, constant ranal amino-aciduria, and other bizarre biochemical features. Lancet, 2,421 .

Bonsnes, R. W. and Taussky, H. H. (1945). On the colorimetric determination of creatinine by the Jaffe reaction. J. biol. Chem., 158,581 .

Brand, E., Harris, M. M. and Biloon, S. (1930). Cystinuria. The excretion of a cystine complex which decomposes in the urine with the liberation of free cystine. ibid., 86, 315.

Bressler, R., Forsyth, B. R. and Klatskin, G. (1960). Serum leucine amino-peptidase activity in hepatobiliary and pancreatic disease. J. Lab. clin. Med., 56, 417.

Carson, N. A. J. and Neill, D. W. (1962). Metabolic abnormalities detected in a survey of mentally backward individuals in Northern Ireland. Arch. Dis. Childh., 37, 505.

Childs, B., Nyhan, W. L., Borden, M., Bard, L. and Cooke, R. E. (1961). Idiopathic hyperglycinemia and hyperglycinuria: a new disorder of amino acid metabolism. Pediatrics, 27, 522.

Cusworth, D. C. and Dent, C. E. (1960). Renal clearances of amino acids in normal adults and in patients with aminoaciduria. Biochem. J., 74, 550.

Dancis, J., Levitz, M. and Westall, R. G. (1960). Maple syrup urine disease: branched-chain keto-aciduria. Pediatrics, 25, 72.

Dent, C. E. (1948). A study of the behaviour of some sixty aminoacids and other ninhydrin-reacting substances on phenol'collidine' filter-paper chromatograms. Biochem. J., 43, 169. (1959). Argininosuccinic aciduria A new form of mental deficiency due to metabolic causes. Proc. roy. Soc. Med., 52, 885.

and Rose, G. A. (1951). Aminoacid metabolism in cystinuria. Quart.J. Med., 20, 205. 
and Senior, B. (1955). Studies on the treatment of cystinuria. Brit. J. Urol., 27, 317 .

uria. and Walshe, J. M. (1954). The pathogenesis of cystincontaining amino-acids. J. clin. Invest., 33, 1216.

and Westall, R. G. (1961). Studies in maple syrup urine disease. Arch. Dis. Childh., 36, 259.

Denys, P., Corbeel, E., Eggermont, E. and Malbrain, H. (1958). Le syndrome de Lowe. Étude de la fonction tubulaire. Pédiatrie, 13, 639.

Eagle, H., Oyama, V. L. and Piez, K. A. (1960). The reversible binding of half-cystine residues to serum protein, and its bearing on the cyst ine requirement of cultured mammalian cells. J. biol. Chem., 235, 1719.

Field, M. B. Carson, N. A. J., Cusworth, D. C., Dent, C. E. and Neill, D. W. (1962). Homocystinuria. A new disorder of metabolism. Abstr. Xth Internat. Congr. Paed. (Lisbon), p. 274.

Fölling, A. (1934). Ưber Ausscheidung von Phenylbrenztraubensäure in den Harn als Stoffwechselanomalie in Verbindung mit Imbezillität. Hoppe-Seylers Z. physiol. Chem., 227, 169.

Frimpter, G. W. (1961). The disulfide of L-cysteine and L-homocysteine in urine of patients with cystinuria. J. hiol. Chem., 236, Pc 51 .

- and Bass, A. (1962). Ion exchange chromatography of some uncommon amino acids. $J$. Chromatog., 7, 427.

Fromageot, C. and Desnuelle, P. (1942). La décomposition anaérobie de l'homocystéine par différents systèmes biologiques; existence d'une homocystéine-désulfurase. C.R. Acad. Sci. (Paris), 214, 647 .

Garrod, A. E. (1923). Inborn Errors of Metabolism, 2nd ed. Oxford University Press, London.

Ghadimi, H., Partington, M. W. and Hunter, A. (1961). A familial disturbance of histidine metabolism. New Engl. J. Med. 265,221 .

Harkness, J., Roper, B. W., Durant, J. A. and Miller, H. (1960). The serum leucine aminopeptidase test. An appraisal of its value in diagnosis of carcinoma of pancreas. Brit. med. J., $1,1787$.

Harris, H., Penrose, L. S. and Thomas, D. H. H. (1959). Cystathioninuria. Ann. hum. Genet., 23, 442.
Hirs, C. H. W., Moore, S. and Stein, W. H. (1952). Isolation of amino acids by chromatography on ion exchange columns; use of volatile buffers. J. biol. Chem., 195, 669 .

Lowe, C. U., Terrey, M. and MacLachlan, E. A. (1952). Organicaciduria, decreased renal ammonia production, hydrophthalmos, and mental retardation. A.M.A.Amer. J. Dis. Child., 83, 164.

McMurray, W. C.. Mohyuddin, F., Rossiter, R. J., Rathbun, J. C. Valentine, G. H., Koegler, S. J. and Zarfas, D. E. (1962). Valentine, G. H., Koegler, S. J. and Zarfas, D. E. (1962) retardation. Lancet, 1 138.

Moore, S., Spackman, D. H. and Stein, W. H. (1958). Chromatography of amino acids on sulfonated polystyrene resins-an improved system. Analyt. Chem., 30, 1185.

Partridge, S. M. (1949). Displacement chromatography on synthetic ion-exchange resins. 3. Fractionation of a protein hydrolysate. Biochem. J., 44, 521 .

Racker E. (1955) Glutathione-homocystine transhydrogenase. J. biol. Chem., 217, 867 .

Reed, G. (1942). The polarographic estimation of cystine in urine. ibid., 142, 61 .

Schafer, I. A., Scriver, C. R. and Efron, M. L. (1962). Familial hyperprolinemia, cerebral dysfunction and renal anomalies occurring in a family with hereditary nephropathy and deafness. New Engl. J. Med., 267, 51 .

Schram, E.. Moore, S. and Bigwood, E. J. (1954). Chromatographic determination of cystine as cysteic acid. Biochem. J., 57, 33 .

Soupart, P., Moore, S. and Bigwood, E. J. (1954). Amino acid composition of human milk. J. biol. Chem., 206, 699.

Spackman, D. H., Stein, W. H. and Moore, S. (1958). Automatic recording apparatus for use in the chromatography of amino acids. Analyt. Chem., 30, 1190.

Stein, W. H. and Moore, S. (1954). The free amino acids of human blood plasma. J. biol. Chem., 211, 915.

Sterkel, R. L. Spencer, J. A., Wolfson, S. K. and Williams-Ashman, H. (1958) Serum isocitric dehydiogenase activity with H. G. (1958). Serum isocitric dehydrogenase activity with
particular reference to liver disease. J. Lab. clin. Med., 52, 176.

Westall, R. G. (1955). The amino acids and other ampholytes of urine-3. Unidentified substances excreted in normal human urine. Biochem. J., 60, 247.

(1961). Tools of Biological Research, Third Series, ed. H. J.

B. Atkins, p. 106. Blackwell, Oxford. 